\title{
A study of primary dental care provision in young children with special reference to deprived communities
}

\author{
Socioeconomic and geographical influences on primary dental care preferences in a population of young children by \\ M. Tickle, G. Moulding, K. Milsom, and A. Blinkhorn Br Dent J 2000; 188: 559-561
}

\section{Objective}

To compare the socioeconomic profiles of children registered in the GDS, with those using the CDS services and unregistered children. Secondly to examine the effects of socioeconomic status on travelling to access primary dental care, and finally to map out the location of unregistered children in relation to primary dental care services.

\section{Setting}

The study was carried out in 1998 in Ellesmere Port in the North West of England.

\section{Subjects and materials}

The study population was all children younger than 6 years who used primary dental care services in, or were residents of,

Ellesmere Port. The study population was categorised into those registered with a GDS dentist, those using CDS services and those unregistered by matching GDS and CDS data to the HA population register. Socioeconomic status was measured using the Super Profiles geodemographic classification. The relationship between service preferences and travelling to access primary dental care with socioeconomic status were compared using cross-tabulations and chi square tests.

\section{Results}

There was a significant socioeconomic trend evident in the use of dental services. Two thirds of those using CDS services came from the most deprived area types. Of those who were unregistered half lived in the most deprived area types compared with one third of those registered with the GDS. Those who travelled into Ellesmere
Port to access primary dental care were significantly more likely to live in an affluent area. Unregistered patients were homogeneously spread across the town.

\section{Conclusions}

The ability to match GDS and CDS data to the HA population register is essential to understand how dental services are used by the local population. Children from deprived areas are more likely to use the CDS and a service local to their homes, therefore primary dental care services for deprived communities have to be provided locally.

\section{Comment}

This paper describes a useful and effec1 tive method of assessing the attendance patterns of children seeking dental care. Because of the conclusion that children under 6 years of age living in deprived areas are less likely to attend general dental practices in comparison with the Community Dental Service (CDS) and also favour locally-sited services, several important issues are raised. Currently general dental practitioners are free to locate their practices in any geographical locality. This can result in a distribution of primary dental care provision related more to dental demand than to dental need. This study suggests that this issue should be addressed if attendance is to be improved for the younger population in more deprived areas. If the profession is to satisfy the needs of the local population, should more control be exercised over the location of primary dental care services as occurs in some other European states? It has been shown that it is possible to establish economically viable practices in areas lacking a good record of patient attendance and that health authorities should therefore encourage new practices in these areas. ${ }^{1}$

If car ownership is a strong proxy for income, more efficient and cheaper public transport may offer an alternative solution for this sector of the community. This could be particularly important in more rural areas. Although dental care is free for all children in both the General Dental Service (GDS) and CDS, adverse publicity associated with the cost of adult NHS and private dental care may exert a negative influence on the attendance of parents with their children at GDS practices.

The public perception of the CDS as being a service for the poor may change with the introduction of the personal den- tal service (PDS) which can bring both systems of healthcare delivery under the same umbrella. This study was carried out shortly before all the GDS dentists in Ellesmere Port became part of a PDS Pilot in October 1998. It would be interesting to see whether this change has any influence on attendance patterns, especially as registration will be one of the measures of success for the Ellesmere Port pilot. This study highlights the importance of evaluation of new methods of healthcare delivery.

\section{R. S. Ireland}

Professor of Primary Dental Care, Liverpool Dental Hospital

1 Lennon M. A., Ingleby J. C., Young P. J. The growth of new practices established in the North West of England and North Wales between 1985 and 1990. Br Dent J 1995; 179: 180-182. 